\title{
High prevalence of poor fluid and supplement knowledge in sports and exercise science \& public health nutrition students
}

\author{
A. Walshe ${ }^{1}$, N. Ryan ${ }^{1}$, L. Ryan ${ }^{1}$ and E. Hannon ${ }^{1}$ \\ ${ }^{1}$ Department of Sport, Exercise, and Nutrition, School of Science and Computing, Galway-Mayo Institute of \\ Technology, Galway, Ireland
}

The current sports nutrition supplement market is being flooded with a plethora of products claiming to enhance athletic performance and wellbeing. Although stimulants and protein supplements are among the most common, electrolyte and carbohydrate-based hydration supplements are beginning to be marketed to Irish athletes and weekend warriors including under-researched seawater products $^{(1)}$. It is difficult to consider the promotion of such supplements as research has consistently shown poor hydration and supplement knowledge in athletic and general populations ${ }^{(2,3)}$. Supplements should only be used to 'supplement' performance, and not to mask misunderstanding or poor hydration strategies. In addition, the effect of education on fluid and supplement knowledge is yet to be investigated in the literature.

The following study aimed to assess current fluid and supplement knowledge in a collegiate cohort. The study also aimed to understand the effect of education on the aforementioned knowledge categories. Zinn's Sports Nutrition Knowledge questionnaire ${ }^{(4)}$ was administered to undergraduate students completing nutrition (PHN) and/or sport and exercise science (SES) programmes at Galway-Mayo Institute of Technology $(\mathrm{N}=71)$, with all responses obtained anonymously. One and two-way ANOVA's assessed the effect of education, gender, and physical activity on fluid and supplement knowledge.

Supplement knowledge was significantly higher in the group which had undertaken the most nutrition modules, $\operatorname{SES} 4,(\mathrm{~F}(3,58)=$ $4.538, p=0.006$ ) compared to all other groups. Mean supplement knowledge score was $35.64 \pm 17.83 \%$. Post hoc Bonferroni pairwise comparisons indicated a significant difference between SES 4, and SES $1(\mathrm{p}=0.013, \mathrm{~d}=1.22), \operatorname{SES} 2(\mathrm{p}=0.037, \mathrm{~d}=1.01)$, PHN $2(\mathrm{p}$ $=0.047, \mathrm{~d}=0.84)$. In addition, a significant moderate positive correlation existed between number of nutrition modules completed and supplement knowledge $(\mathrm{p}=0.001, \mathrm{r}=0.418)$. The effects of education on fluid knowledge was equivocal across groups, mean fluid knowledge score was $55.09 \pm 16.53 \%$. A significant difference in fluid knowledge was evident between groups, $(\mathrm{F}(2,67)=4.02, \mathrm{p}=$ 0.011). Post hoc Bonferroni pairwise comparisons identified a significant difference between the SES 1 and SES $2(p=0.028, d=$ $0.87)$, and PHN $2(p=0.032, d=1.10)$. No correlation existed between number of nutrition modules completed and fluid knowledge $(p=0.124, r=0.184)$. Gender and participation in sport had no effect on questionnaire results $(p>0.05)$.

To conclude, although education may affect fluid and supplement knowledge, in the current study it did not prevent insufficient knowledge in students. This study highlights the importance of accreditation in Sports Nutrition before providing recommendations to athletes ${ }^{(3)}$, especially where athletes undergo drug testing.

\section{References}

1. Perez-Turpin JA, Trottini M, Chinchilla-Mira JJ, et al. (2017) Biol Sport 34(4), 407-412.

2. Magee PJ, Gallagher AM \& McCormack JM (2017) Int J Sport Nutr Exerc Metab 27(2), 158-168.

3. Cockburn E, Fortune A, Briggs M, et al. (2014) Nutrients 6, 1442-1453.

4. Zinn C, Schofield G \& Wall C (2005) J Sci Med Sport 8(3), 346-351. 